\title{
Motilidade espermática, fertilização dos ovócitos e eclosão dos ovos de jundiá em água contaminada por cádmio
}

\author{
Laurentina Witeck ${ }^{1}$, Robie Allan Bombardelli ${ }^{1}$, Eduardo Antônio Sanches ${ }^{2}$, José Dilson Silva \\ de Oliveira ${ }^{1}$, Diego Mendes Baggio ${ }^{1}$, Bruno Estevão de Souza ${ }^{3}$
}

\footnotetext{
${ }^{1}$ Centro de Engenharias e Ciências Exatas, Universidade Estadual do Oeste do Paraná, Toledo/PR

2 Centro de Aqüicultura, Universidade Estadual Paulista Júlio de Mesquita Filho, Jaboticabal/SP.

3 Instituto Federal do Paraná, Foz do Iguaçu/PR.
}

RESUMO - Este estudo foi realizado para avaliar o efeito da contaminação da água por cádmio sobre a taxa de fertilização dos ovócitos e de eclosão dos ovos e a duração da motilidade espermática em jundiá (Rhamdia quelen). Foram realizados dois ensaios: no ensaio 1, foi avaliado o efeito do cádmio sobre a fertilização artificial dos ovócitos e a eclosão dos ovos e, no ensaio 2, o efeito do cádmio sobre a duração da motilidade espermática. Em ambos os ensaios, adotou-se o delineamento experimental inteiramente casualizado com cinco níveis de cádmio na água $\left(0 ; 20 ; 50 ; 80\right.$ e $110 \mathrm{mg} \mathrm{L}^{-1}$ ), avaliados com quatro (ensaio 1) ou três repetições (ensaio 2). As taxas de fertilização e eclosão tiveram resposta linear, mantendo-se constantes até os níveis de 28,6 e 40,4 $\mathrm{mg} \mathrm{L}^{-1}$, respectivamente. A partir desses níveis, ocorreu um efeito linear inversamente proporcional entre as taxas de fertilização e eclosão e o aumento dos níveis de cádmio. O aumento do nível de cádmio na água teve efeito linear inverso na duração da motilidade espermática, proporcionando redução de 21,8s em água limpa para 10,6s em água contaminada contendo $110 \mathrm{mg}^{-1}$. Níveis a partir de 20,0 e $28,6 \mathrm{mg} \mathrm{L}^{-1}$ influenciam espermatozoides e ovócitos de jundiá, respectivamente.

Palavras-chave: bagre, fertilização artificial, metal pesado, peixes, Rhamdia quelen, sêmen

\section{Sperm motility, oocyte fertilization and egg hatching on jundiá catfish in cadmium contaminated water}

\begin{abstract}
The objective of this work was to evaluate the effect of water contaminated by cadmium on the rates of oocyte fertilization and egg hatching, and sperm motility duration on jundiá catfish (Rhamdia quelen). Two trials were performed: in trial 1, it was evaluated the effect of cadmium on the artificial fertilization of oocytes and egg hatching and in trial 2, the effects of cadmium on the sperm motility duration were evaluated. In both trials, it was used a completely randomized experimental design with five levels of cadmium in the water $\left(0 ; 20 ; 50 ; 80\right.$ and $\left.110 \mathrm{mg} \mathrm{L}^{-1}\right)$ evaluated with four (trial 1) or three replicates (trial 2). Fertilization and hatching rates showed linear response, remaining constant up to the levels of 28.6 and $40.4 \mathrm{mg} \mathrm{L}^{-1}$, respectively. From these levels, a linear effect inversely proportional between the fertilization and hatching rates and an increase in the levels of cadmium occurred. The increase on the level of cadium in the water had an inverse linear effect of sperm motility duration providing a reduction from $21.8 \mathrm{~s}$ in clean water to $10.6 \mathrm{~s}$ in contaminated water containing $110 \mathrm{mg} \mathrm{L}^{-1}$. Levels from 20.0 to $28.6 \mathrm{mg} \mathrm{L}^{-1}$ influence sperm and oocytes of jundiá catfish, respectively.
\end{abstract}

Key Words: artificial fertilization, catfish, fish, metal, Rhamdia quelen, semen

\section{Introdução}

O jundiá (Rhamdia quelen) é uma espécie de peixe reofílica pertencente à ordem Siluriformes (Nakatani et al., 2001) encontrado nas Américas Central e do Sul (Silfvergrip, 1996; Baldisserotto, 2004). É uma espécie nativa capaz de tolerar baixas temperaturas, apresentando bom crescimento no inverno e verão, principalmente, no sul do Brasil (Piaia \& Baldisserotto, 2000), alto rendimento de carcaça, carne de ótimo sabor (Barcelos et al., 2003) e boa aceitação no mercado consumidor (Marchioro \& Baldisserotto, 1999).

Apesar do processo reprodutivo do jundiá estar praticamente dominado (Huergo \& Zaniboni Filho, 2006), alguns estudos envolvendo práticas reprodutivas ainda são necessários (Bombardelli et al., 2006), especialmente no que diz respeito à qualidade dos gametas e suas interações com o ambiente (Hilbig et al., 2008). A exemplo disso, estudos apresentam influências dos metais pesados sobre a reprodução de peixes (Kime, 1995; Sumpter, 1997), 
especialmente na qualidade dos gametas (Kime et al., 1996; Lahnsteiner et al., 2004), na fertilização dos ovócitos (Rurangwa et al., 1998; Hilbig, 2008) e na qualidade das larvas (Jezierska et al., 2000; Sarnowski, 2004).

Nos peixes teleósteos com fertilização externa, no momento em que ocorre a desova, os gametas são lançados no ambiente para que ocorra a fertilização. Nesse instante, os gametas estão expostos a vários contaminantes presentes na água, entre eles, os metais pesados mercúrio, zinco, chumbo, cobre e cádmio (Kime \& Nash, 1999). Esses elementos-traço, em certos níveis, prejudicam a motilidade dos espermatozoides e a fertilização dos ovócitos (Kime, 1995).

O objetivo neste trabalho foi avaliar os efeitos da contaminação da água por cádmio sobre as taxas de fertilização dos ovócitos, a eclosão dos ovos e a duração da motilidade espermática de jundiás (Rhamdia quelen).

\section{Material e Métodos}

O experimento foi conduzido no Laboratório de Tecnologia da Reprodução de Animais Aquáticos Cultiváveis (LATRAAC) da Universidade Estadual do Oeste do Paraná (UNIOESTE), instalado no Centro de Pesquisa em Aqüicultura Ambiental (CPAA), Toledo/PR.

Quatro fêmeas e três machos de jundiá (Rhamdia quelen) provenientes da estação de pesquisa foram macroscopicamente selecionados no tanque de cultivo utilizando-se como critérios, nas fêmeas, abdômen arredondado, papila urogenital avermelhada, coloração e tamanho dos ovócitos uniformes e, nos machos, presença de sêmen. Os ovócitos e o sêmen foram coletados por meio de leve pressão abdominal no sentido céfalo-caudal.

Após a seleção, os reprodutores foram levados ao laboratório, pesados, medidos, marcados e separados por sexo em tanques circulares de $1.500 \mathrm{~L}$ com renovação constante da água $\left(750 \mathrm{~L} \mathrm{~h}^{-1}\right)$. Machos e fêmeas apresentavam $431,67 \pm 35,47 \mathrm{~g} ; 481,25 \pm 293,21 \mathrm{~g} ;$ e $28,17 \pm 4,04 \mathrm{~cm}$; $27,25 \pm 5,17 \mathrm{~cm}$, respectivamente.

Os peixes foram induzidos com aplicação de extrato bruto de hipófise de carpa (EBHC). Machos e fêmeas receberam uma dose única de 3,0 mg e 5,5 mg de EHC. $\mathrm{kg}^{-1}$ de reprodutor, respectivamente. As aplicações foram realizadas no músculo, próximo à nadadeira dorsal (Bombardelli et al., 2006). Após 240 horas-grau ou unidades térmicas acumuladas, realizaram-se as coletas dos gametas. Para isso, os indivíduos foram contidos e secos com panos e papel-toalha. Em seguida foi realizada massagem na região ventral em sentido céfalo-caudal. A coleta do sêmen foi realizada em tubo de ensaio graduado de $10 \mathrm{~mL}$, para mensuração do volume total coletado, e os ovócitos foram coletados em placas de Petri.

A partir do sêmen coletado dos reprodutores, preparou-se um pool e realizaram-se as análises de concentração espermática e do tempo de duração da motilidade espermática. A análise de concentração espermática foi realizada mediante contagem de células espermáticas em câmara hematimétrica de Neubauer, após a fixação dos espermatozoides em formol salino tamponado a uma diluição de 1:1000 (sêmen:fixador) conforme Hilbig et al. (2008).

Nos ensaios de fertilização, foram utilizados $40 \mathrm{~mL}$ de ovócitos provenientes do pool de todas as fêmeas. Foi utilizado um delineamento experimental inteiramente casualizado,composto por cinco fatores em estudo e quatro repetições (20 unidades experimentais). Os fatores foram constituídos pelo emprego de água contaminada por cádmio, como solução ativadora dos gametas, nos níveis de $0 ; 20$; $50 ; 80 ; \mathrm{e} 110 \mathrm{mg} \mathrm{de} \mathrm{L}^{-1}$. Considerou-se unidade experimental uma incubadora (2,5L de volume útil), contendo $2,0 \mathrm{~mL}$ de ovócitos ( 2.710 ovócitos) fertilizados com $0,1 \mathrm{~mL}$ de sêmen $\left(1,7174 \times 10^{6}\right.$ espermatozoides.ovócito $\left.{ }^{-1}\right)$, com adaptação ao descrito por Bombardelli et al. (2006). O volume de solução ativadora empregada para a fertilização dos ovócitos foi de $10 \mathrm{~mL}$ durante um minuto. Antes de iniciar o processo de incubação, os ovócitos foram lavados diversas vezes em água isenta do metal, com o intuito de retirar o cádmio presente na água utilizada no processo de fertilização artificial. Após a fertilização, os ovos foram levados para as incubadoras experimentais ligadas a um sistema de recirculação de água isenta de contaminantes contendo os respectivos valores: $\mathrm{pH}=6,80$; oxigênio dissolvido $=$

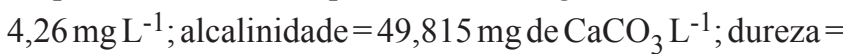
$43,96 \mathrm{mg} \mathrm{de} \mathrm{CaCO}_{3} \mathrm{~L}^{-1}$; amônia total $=0,126 \mathrm{mg} \mathrm{L}^{-1}$; nitrito $=$ $0,0038 \mathrm{mg} \mathrm{L}^{-1}$; nitrato $=0,29 \mathrm{mg} \mathrm{L}^{-1}$. A temperatura da água do sistema de incubação foi de $27,5 \pm 1{ }^{\circ} \mathrm{C}$ e foi controlada por meio de sistema de resistência elétrica e termostato e mensurada de hora em hora.

Após o fechamento do blastóporo (oito horas após a fertilização) (Amorim et al., 2009), foram estimadas as taxas de fertilização por contagem em microscópio estereoscópico (aumento de 20X) de três amostras de aproximadamente 200 ovos de cada unidade experimental. A taxa de eclosão dos ovos foi mensurada 24 horas após a fertilização, por meio da estimativa do número total de larvas de cada unidade experimental.

Também foi mensurado o efeito das mesmas soluções contaminadas por cádmio sobre o tempo de motilidade espermática, avaliado utilizando-se uma diluição de 1:40 
(sêmen:solução ativadora). Após a ativação, $5 \mu \mathrm{L}$ do material foram analisados em microscopia de luz (objetiva 40X), registrando-se o tempo transcorrido até a perda do movimento de $50 \%$ dos espermatozoides, conforme relatos de Sanches et al. (2009). Para essa avaliação, foi utilizado delineamento experimental inteiramente casualizado com três repetições para cada nível de contaminação por cádmio.

Os resultados das taxas de fertilização e eclosão e do tempo de motilidade espermática foram submetidos à análise de regressão a 5\% de significância utilizando-se o software o SAEG - Sistema de Análises Estatísticas e Genéticas (UFV, 1997).

\section{Resultados e Discussão}

O sêmen utilizado no experimento apresentou concentração espermática de $4,6525 \times 10^{10}$ espermatozoides $\mathrm{mL}^{-1}$ e tempo de motilidade espermática em água limpa de $21,86 \pm 1,33 \mathrm{~s}$. Resultados similares foram encontrados por Bombardelli et al. (2006), que observaram concentração espermática de $1,97 \times 10^{10} \mathrm{~mL}^{-1}$ em indivíduos da mesma espécie, e por Hilbig et al. (2008), que registraram motilidade em água limpa de 27,2 segundos.
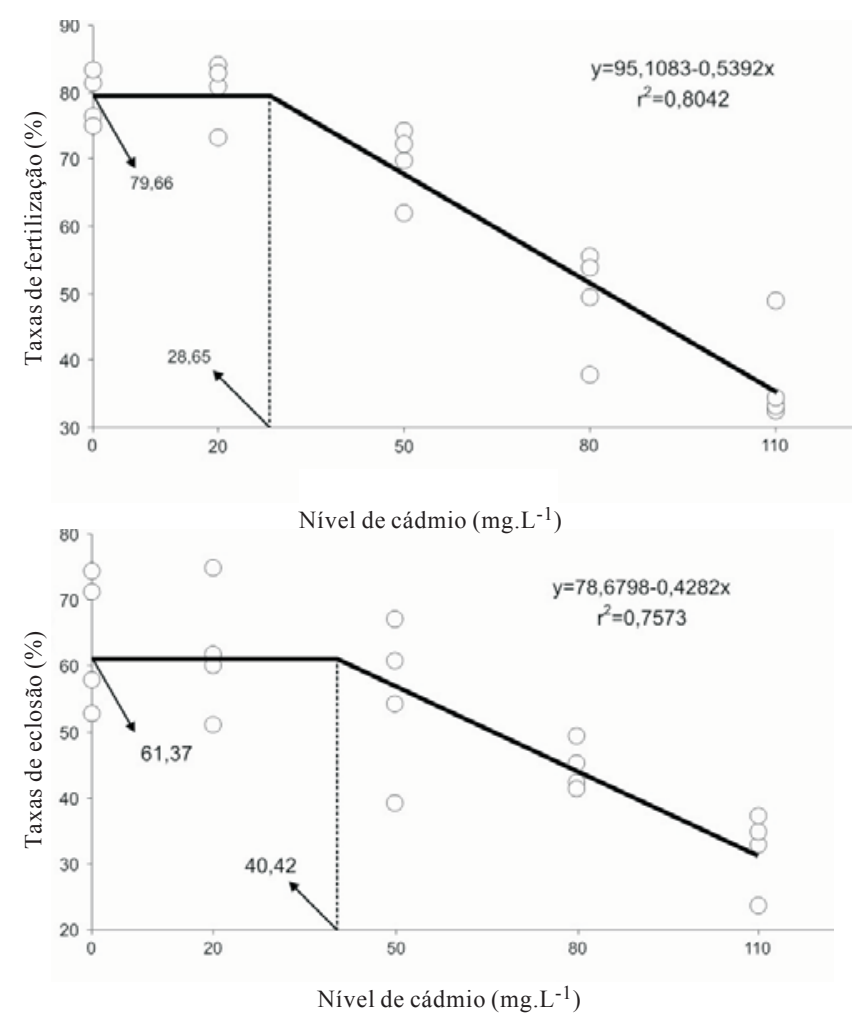

Figura 1 - Taxas de fertilização dos ovócitos e de eclosão de ovos de jundiá fertilizados artificialmente em água contaminada com cádmio.
Os níveis de cádmio na água tiveram efeito linear $(\mathrm{P}<0,05)$ sobre as taxas de fertilização (Figura 1), fato que sugere ausência de efeito entre os níveis de cádmio até a concentração de $28,65 \mathrm{mg} \mathrm{L}^{-1}$, mantendo-se a média de $79,66 \%$ dos ovócitos fertilizados. A partir dessa concentração, os resultados mostraram efeito $(\mathrm{P}<0,05)$ linear inversamente proporcional aos níveis crescentes de cádmio. Comportamento semelhante foi verificado por Hilbig et al. (2008), que, testando diferentes níveis de chumbo, observaram que a contaminação da água de fertilização artificial e incubação dos ovos com níveis de chumbo superiores a $0,25 \mathrm{mg} \mathrm{L}^{-1}$ reduziu as taxas de fertilização de ovócitos de Rhamdia quelen.

As taxa de eclosão tiveram comportamento semelhante ao da taxa de fertilização, no entanto, a dose de cádmio que iniciou a redução das taxas de eclosão foi de $40,42 \mathrm{mg} \mathrm{L}^{-1}$ (Figura 1). A causa dessa redução das taxas de fertilização e de eclosão (Figura 1) pode ter sido as injúrias causadas pelo causadas pelo cádmio sobre as membranas dos gametas e/ou ovos embrionados (Brooks et al., 1997). Almeida et al. (2002) sugeriram que o cádmio pode ter esse efeito devido ao seu alto potencial de oxirredução, decorrente da liberação de radicais livres de oxigênio.

Rurangwa et al. (1998) notaram efeito semelhante quanto à redução das taxas de fertilização e eclosão em ovócitos de Clarias gariepinus em água contaminada por mercúrio. Observaram também efeito a partir de $0,1 \mu \mathrm{g} \mathrm{L}^{-1}$ e morte total dos embriões em concentração de $10,0 \mathrm{mg} \mathrm{L}^{-1}$. Segundo esses autores, pequenos níveis de mercúrio na água reduzem as taxas de fertilização por diminuírem a motilidade espermática. Isso foi confirmado com a aplicação de diferentes doses inseminantes, com e sem mercúrio, na água. Todavia, o aumento da relação espermatozoide:água mascara o efeito do mercúrio sobre as taxas de fertilização, indicando que as concentrações aplicadas não foram suficientes para proporcionar efeitos deletérios sobre os ovócitos, mas sim sobre os espermatozoides. Assim, pode-se afirmar que a relação de 1,717.400:1 (espermatozoides:ovócito) aplicada neste experimento é influenciada em nível a partir de $28,65 \mathrm{mg} \mathrm{L}^{-1}$ e, possivelmente, a aplicação de doses inseminantes inferiores ocasionará redução nas taxas de fertilização em concentrações inferiores de cádmio na água. Todavia, estudos relacionados a possíveis interações entre as variáveis ainda devem ser realizados para que se possa elucidar estes efeitos no jundiá cinza.

Os tempos de duração da motilidade espermática apresentaram efeito $(\mathrm{P}<0,05)$ linear inversamente proporcional com os crescentes níveis de cádmio utilizados na ativação dos espermatozóides (Figura 2). Possivelmente 


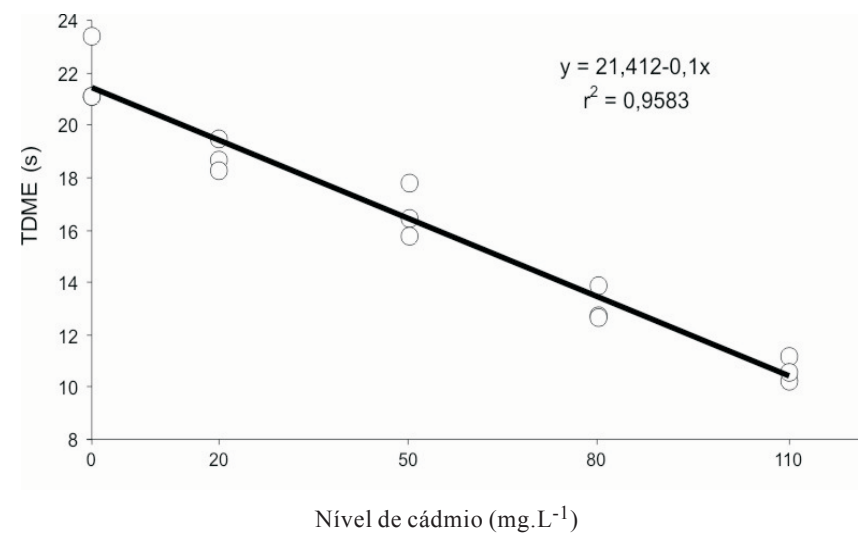

Figura 2 - Tempo de duração da motilidade espermática de Rhamdia quelen em função de diferentes níveis de cádmio empregados na água durante o processo de ativação espermática.

a redução do tempo de motilidade (Figura 2) colaborou para a redução das taxas de fertilização e eclosão (Figura 1). Resultados semelhantes foram verificados por Hilbig et al. (2008), os quais observaram redução da motilidade de 27,2s em água desprovida de chumbo para 21,0 s em água contendo o metal na concentração de $0,75 \mathrm{mg} \mathrm{L}^{-1}$.

De acordo com Van Look \& Kime (2003), em peixes os gametas masculinos são mais suscetíveis aos poluentes, uma que a ativação é rápida e seu movimento se inicia com o contato com a água. Vários efeitos têm sido observados em espermatozoides expostos aos metais pesados, como alterações morfológicas e redução da motilidade espermática (Rurangwa et al., 2004), proporcionando redução das taxas de fertilização artificial dos ovócitos (Kime \& Nash, 1999).

Abascal et al. (2007), em experimento realizado com Dicentrarchus labrax, observaram inibição da motilidade espermática em concentrações de $\mathrm{HgCl}_{2}$ de $100 \mathrm{mg} \mathrm{L}^{-1}$. Observaram, ainda, relação inversamente proporcional entre a velocidade de deslocamento linear dos espermatozoides e o aumento dos níveis de mercúrio na solução ativadora. Segundo esses autores, os espermatozoides expostos a soluções contendo mercúrio apresentaram graves alterações morfológicas flagelares, principalmente devido à perda da membrana flagelar.

Van Look \& Kime (2003) verificaram que a exposição dos espermatozoides de peixes em soluções crioprotetoras por 24 horas contendo crescentes níveis de cloreto de mercúrio causou injúrias nos espermatozoides e essas injúrias afetaram a motilidade dos espermatozoides, principalmente porque causaram diminuição do comprimento flagelar e aumento do tamanho da cabeça dos espermatozoides. Os autores atribuíram essas alterações ao fato de o mercúrio causar o rompimento dos microtubos que constituem os flagelos e da membrana plasmática que envolve a cabeça dos espermatozoides, promovendo assim um influxo de íons e soluções no interior da célula espermática. Rurangwa et al. (1998) observaram que espermatozoides expostos ao mercúrio apresentam caudas quebradas e em formas de espiral.

Assim como o chumbo e o mercúrio, o cádmio também pode causar redução da motilidade espermática e das velocidades dos espermatozoides de peixes. Esses efeitos sobre os espermatozoides foram estudados por Lahnsteiner et al. (2004), que observaram sensibilidade dos espermatozoides das espécies Clarias gariepinus, Salmo trutta fario e Lota lota à exposição por cádmio. Nessas espécies, houve redução da taxa de motilidade espermática, enquanto na Salmo trutta fario ocorreu também redução da velocidade espermática. Além disso, os autores observaram que a alteração da motilidade espermática nestas espécies ocorreu em níveis de cádmio a partir de $25 \mathrm{mg} \mathrm{L}^{-1}$. Efeitos semelhantes nas características espermáticas dessas espécies foram evidenciados também para o chumbo, zinco e mercúrio.

Espermatozoides de peixes, quando expostos a soluções crioprotetoras contendo níveis crescentes de cloreto de zinco e cádmio, sofreram redução da motilidade espermática e alterações de movimento, e os níveis limitantes para a qualidade espermática foram de $2.000 \mathrm{ppm}$ de zinco e 100 ppm de cádmio (Kime et al., 1996).

Apesar das dificuldades encontradas na mensuração da motilidade espermática, devido ao curto período de movimentação (Billard \& Cosson, 1992), os espermatozoides de peixes são ótimos indicadores para ensaios de toxicidade, pois são altamente sensíveis a poluentes e sua utilização é vantajosa por não exigir sacrifício de animais para os testes (Kime et al., 1996).

\section{Conclusões}

A contaminação da água de fertilização com cádmio em níveis de até $28,65 \mathrm{mg} \mathrm{L}^{-1}$ não reduz as taxas de fertilização e eclosão dos ovos. No entanto, concentrações superiores a 20,0 $\mathrm{mg} \mathrm{L}^{-1}$ provocam redução da motilidade espermática em jundiá (Rhamdia quelen).

\section{Referências}

ABASCAL, F.J.; COSSON, J.; FAUVEL, C. Characterization of sperm motility in sea bass: the effect of heavy metals and physicochemical variables on sperm motility. Journal of Fish Biology, v.70, p.509-522, 2007. 
ALMEIDA, J.A.; DINIZB, Y.S.; MARQUESA, S.F.G. et al. The use of oxidative stress responses as biomarkers in Nile tilápia (Oreochromis niloticus) exposed to in vivo cadmium contamination. Environment International, v.27, p.673-679, 2002 .

AMORIM, M.P.; GOMES, B.V.C.; MARTINS, Y.S. et al. Early development of the silver catfish Rhamdia quelen (Quoy \& Gaimard, 1824) (Pisces:Heptapteridae) from the São Francisco River Basin, Brazil. Aquaculture Research, v.40, n.2, p.172-180, 2009.

BALDISSEROTO, B. Biologia do jundiá. In: BALDISSEROTO, B.; RADÜNZ NETO, J. (Eds.) Criação de jundiá. Santa Maria: Editora UFSM, 2004. 232p.

BARCELlos, L.J.G.; KREUTZ, L.C.; RODRIGUES, L. et al. Hematological and biochemical characteristics of male jundiá, Rhamdia quelen (Quoy \& Gaimard pimelodidae): change after acute stress. Aquaculture Research, v.34, p.1465-1469, 2003.

BILLARD, R.; COSSON, M.P. Some problems related to the assessment of sperm motility in freshwater fish. The Journal of Experimental Zoology, v.261, p.122-131, 1992.

BOMBARDELLI, R.A.; MÖRSCHBÄCHER, E.F.; CAMPAGNOLO, R. et al. Dose inseminante para fertilização artificial de ovócitos de jundiá Rhamdia quelen (Quoy \& Gaimardm, 1824). Revista Brasileira de Zootecnia, v.35, n.4, p.1251-1257, 2006.

BROOKS, S.; TYLER, C.R.; SUMPTER, J.P. Egg quality in fish: what makes a good egg? Reviews in Fish Biology and Fisheries, v.7, p.387-416, 1997.

HILBIG, C.C.; BOMBARDELLI, R.A.; SANCHES, E.A. et al. Efeito do chumbo sobre a fertilização artificial e incubação de ovos de jundiá cinza (Rhamdia quelen). Acta Scientiarum, Animal Sciences, v.30, n.2, p.217-224, 2008.

HUERGO, G.M.; ZANIBONI FILHO, E. Triploidy induction in jundia, Rhamdia quelen (Quoy \& Gaimard, 1824), through hydrostatic pressure shock. Journal of Applied Aquaculture, v. 18, p. $45-57,2006$.

JEZIERSKA, B.; LUGOWSKA, K.; WITESKA, M. et al. [2000] Malformations of newly hatched common carp larvae. Electronic Journal of Polish Agricultural Universities, Fisheries, v.3, n.2, 2000. Disponível no site: <http:// www.ejpau.media.pl>. Acesso em: 19/05/2007.

KIME, D.E.; NASH, J.P. Gamete viability as an indicator of reproductive endocrine disruption in fish. The Science of the Total Environment, v.233, p.123-129, 1999.

KIME, D.E. The effects of pollution on reproduction in fish. Reviews in Fish in Biology and Fishers, v.5, p.52-96, 1995.

KIME, D.E.; EBRAHIMI, M.; NYSTEN, K. et al. Use of computer assisted sperm analysis (CASA) for monitoring the effects of pollution on sperm quality of fish; application to the effects of heavy metals. Aquatic Toxicology, v.36, p.223-237, 1996.

LAHNSTEINER, F.; MANSOUR, N.; BERGER, B. The effect of inorganic and organic pollutants on sperm motility of some freshwater teleosts. Journal of Fish Biology, v.65, p.12831297, 2004.

MARCHIORO, M.I.; BALDISSEROTTO, B. Sobrevivência de alevinos de jundiá (Rhamdia quelen Quoy \& Gaimard, 1824) à variação de salinidade da água. Ciência Rural, v.29, n.2, p.315$318,1999$.

NAKATANI, K.; AGOSTINHO, A.A.; BAUMGARTNER, G. et al. Ovos e larvas de peixes de água doce. Maringá: EDUEM, 2001. 378p.

PIAIA, R.; BALDISSEROTO, B. Densidade de estocagem e crescimento de alevinos de jundiá Rhamdia quelen (Quoy \& Gaimard, 1824). Ciência Rural, v.30, n.3, p.509-513, 2000 .

RURANGWA, E.; KIME, D.E.; OLlEVIER, F. et al. The measurement of sperm motility and factors affecting sperm quality in cultured fish. Aquaculture, v.234, p.1-28, 2004.

RURANGWA, E.; ROCLANTS, I.; HUYSKENS, G. et al. The minimum effective spermatozoa:egg ratio for artificial insemination and the effects of mercury on sperm motility and fertilization ability in (Clarias gariepinus). Journal of Fish Biology, v.53, p.402-413, 1998.

SANCHES, E.A.; BOMBARDELLI, R.A.; BAGGIO, D.M. et al. Dose inseminante para fertilização artificial de ovócitos de dourado. Revista Brasileira de Zootecnia, v.38, n.11, p.2091-2098, 2009.

SARNOWSKI, P. [2004]. The effects of metals on swimbladder inflation of common carp (Cyprinus carpio 1.) larvae. Electronic Journal of Polish Agricultural Universities, Fisheries, v.7, n.1, 2004. Disponível em: <http:// www.ejpau.media.pl>. Acesso em: 19/5/2007.

SILFVERGRIP, A.M.C. A sistematic revision of the neotropical catfish genus Rhamdia (teleostei, pimelodidae). 1996. 156f. Thesis (Doctorship in Zoology) - Swedish Museum of natural History, Stockholm.

SUMPTER, J.P. Environmental control of fish reproduction: a different perspective, Fish Physiology and Biochemistry, v.17, p.25-31, 1997.

UNIVERSIDADE FEDERAL DE VIÇOSA - UFV. Sistema para análises estatísticas e genéticas - SAEG. Versão 7.1. Viçosa, MG 1997. 150p. (Manual do usuário).

VAN LOOK, K.J.W.; KIME, D.E. Automated sperm morphology analysis in fishes: the effect of mercury on goldfish sperm, Journal of Fish Biology, v.63, p.1020-1033, 2003. 